\title{
WestVirginiaUniversity
}

THE RESEARCH REPOSITORY @ WVU

Graduate Theses, Dissertations, and Problem Reports

2001

\section{Effects of reinforcement delays on procrastination in pigeons}

\author{
Megan Elizabeth Meginley
}

West Virginia University

Follow this and additional works at: https://researchrepository.wvu.edu/etd

\section{Recommended Citation}

Meginley, Megan Elizabeth, "Effects of reinforcement delays on procrastination in pigeons" (2001). Graduate Theses, Dissertations, and Problem Reports. 708.

https://researchrepository.wvu.edu/etd/708

This Thesis is protected by copyright and/or related rights. It has been brought to you by the The Research Repository @ WVU with permission from the rights-holder(s). You are free to use this Thesis in any way that is permitted by the copyright and related rights legislation that applies to your use. For other uses you must obtain permission from the rights-holder(s) directly, unless additional rights are indicated by a Creative Commons license in the record and/ or on the work itself. This Thesis has been accepted for inclusion in WVU Graduate Theses, Dissertations, and Problem Reports collection by an authorized administrator of The Research Repository @ WVU. For more information, please contact researchrepository@mail.wvu.edu. 


\title{
Effects of Reinforcement Delays on Procrastination in Pigeons
}

\author{
Megan E. Meginley \\ Thesis submitted to the \\ College of Arts and Sciences \\ At West Virginia University \\ for the degree of \\ Master of Arts \\ in \\ Psychology
} in partial fulfillment of the requirements
Kennon A. Lattal, Ph.D., Chair
Michael Perone, Ph.D.
Cheryl McNeil, Ph.D.
Department of Psychology
Morgantown, West Virginia
2001

Keywords: Procrastination, Pigeons, Reinforcement Delay, Self-Control 


\section{ABSTRACT \\ Effects of Reinforcement Delays \\ On Procrastination in Pigeons}

Megan E. Meginley

Procrastination has been defined as the choice of a larger, later work requirement over a smaller, sooner work requirement. In one experiment (Mazur, 1996), pigeons chose a later-onset work requirement over an earlier-onset work requirement when work requirements were identical and reinforcement was at an equal delay from the choice point. In Phase 1 of the present experiment, reinforcement was delivered to pigeons immediately upon completion of either an early- or a late-onset work requirement in the terminal links of a concurrent-chains schedule. The early-onset work requirement was preferred. This preference held in Phase 2, when a delay to reinforcement was added, following completion of the early-onset work requirement. These results suggest that when work requirements produce more immediate reinforcement, relative to the choice point, they will be preferred, even when there is a shorter delay to their onset. 


\section{Acknowledgements}

I first would like to thank my committee: Andy Lattal, Mike Perone, and Cheryl McNeil. I especially thank Andy for his ongoing advice and guidance, while at the same time his nurturing of my independence. He let me take my ideas and run with them (for better or for worse), and I thank him for that.

I also would like to thank my labmates, Adam Doughty and Stephanie da Silva, who have been wonderful companions to me, at work and at play. We have had countless exciting discussions about everything from procrastination to the avant-garde, and I have learned so much from them. I was lucky to have been in the Lattal lab at the same time that they were. 
Table of Contents

Acknowledgements




\section{List of Figures}

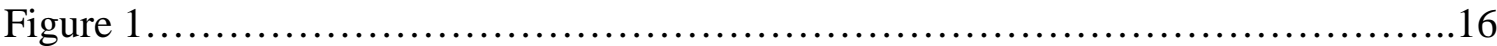

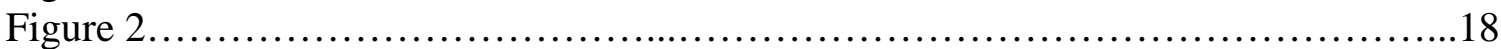

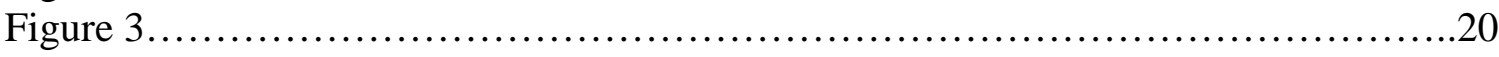

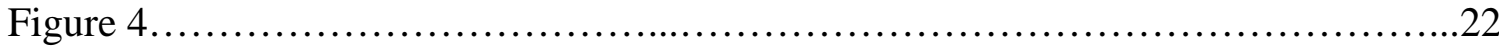


List of Tables

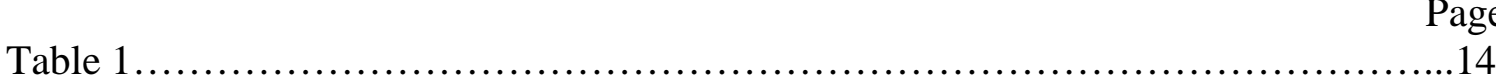

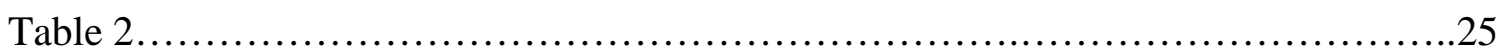

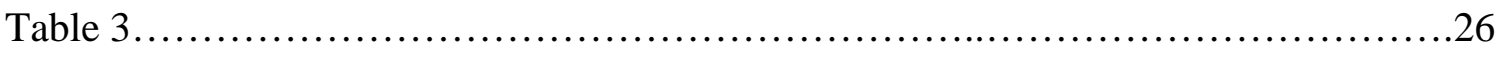


Introduction

"Procrastination" is a familiar term in everyday language and often connotes something undesirable, or even reprehensible. Procrastination often is considered a lack of "self-discipline" and a "roadblock to success." Examples of procrastination abound in everyday settings, from the student who puts off an assignment until the night before it is due, to the cat owner who avoids cleaning the litter box until the odor is unbearable. The reprehensibility sometimes associated with procrastination stems from the fact that the consequences of procrastinating are often detrimental; the student may receive a lower grade when he or she has spent the wee hours of the night working, and the time spent cleaning the litter box is considerably greater after two weeks than after two days. In addition to the decreased reinforcement magnitude or increased work requirement that often are associated with procrastination, the probability of reinforcement may decrease with procrastination as well. The student mentioned above may have the assignment completed (and even done well) an hour before class begins, but if the computer crashes or the printer breaks, that student is disadvantaged relative to the student who had completed the work days before.

Although dictionary and vernacular definitions of procrastination as "the postponement of something that should be done" (Britannica-Webster, 1981, p. 720) are familiar to many, Mazur (1996) provides an operational definition of procrastination from a behavior-analytic perspective. He describes procrastination as the choice of a larger, more delayed work requirement over a smaller, more immediate work requirement. This definition has several advantages. First, it provides a description of behavior that can be observed and measured experimentally. Second, it suggests procedures that can be implemented in non-human, laboratory analogues to simulate procrastination in human, non-laboratory settings. Third, it builds a procedural and conceptual bridge between procrastination and self-control, which is defined in behavioral psychology as the choice of a larger, more delayed reinforcer over a smaller, more immediate reinforcer. With aversive events, self-control is defined as the choice of a smaller, sooner aversive event over a larger, later aversive event. Thus these two descriptions of self-control refer to analogous but opposite effects, and procrastination, as defined by Mazur, fits neatly into the latter. With Mazur's definition as a procedural starting point, procrastination can be studied in attempts to uncover the environmental contingencies that maintain these choices for larger, later work requirements.

A fourth advantage of adopting Mazur's (1996) operational definition of procrastination is that basic nonhuman animal studies in controlled experimental situations can be extrapolated directly to applied situations with human problematic behavior. Although procrastination as the problematic behavior in its own right has not been studied from a behavior-analytic perspective in applied human settings, self-control and impulsivity have been examined in applied behavior analysis in recent years (Vollmer, Borrero, Lalli \& Daniel, 1999). Results from self-control studies with both humans and nonhumans have been used in the assessment and treatment of severe aggressive behaviors and excessive off-task behaviors (Dixon et al., 1998; Vollmer et al., 1999). Impulsivity is seen in many areas of human behavior (e.g., overeating, gambling, 
excessive financial spending), and basic research studies have been designed to answer some of the questions regarding the environmental contingencies that maintain such behavior. Because procrastination is so widely observed in humans, and viewed as problematic, studies designed to isolate the environmental variables that maintain procrastination may be of great applied value as well.

\section{Literature Review}

The study of procrastination as the choice of a larger, later work requirement over a smaller, sooner work requirement stems from several distinct but interrelated areas of research. The largest body of relevant research here is that of self-control and impulsivity. Following Rachlin and Green's (1972) work on commitment and selfcontrol and Ainslie's (1974) work on impulse control in pigeons, many researchers have attempted to isolate the environmental variables that influence impulsivity and selfcontrol involving positively reinforcing consequences. Self-control choice experiments also have been conducted using aversive consequences rather than positive reinforcers. There is evidence that delayed reinforcers and delayed aversive events can function in a parallel, but opposite, way (e.g., Deluty, 1978), and the similarities between self-control with hedonically positive and negative events will be emphasized in this review. In addition, the study of self-control involving aversive consequences is pertinent to an analysis of procrastination that maintains that work requirements themselves are aversive events. Such an assertion therefore also requires that work requirements can in fact function as aversive events, and several lines of evidence support this claim.

\section{Procedures Used to Study Self-Control and Procrastination}

Concurrent-chains schedules often have been used to study choice and preference (e.g., Green \& Snyderman, 1980; Ito \& Asaki, 1982; Leung \& Winton, 1988). In such a procedure, two equal schedules operate in initial links (e.g., on two levers or keys in an operant chamber). Completion of the response requirement in either of the initial links results in entrance into the corresponding terminal link. The terminal links in the two alternatives differ from one another in some way. In some procedures, multiple responses are required in the initial links [e.g., a variable-interval (VI) schedule is operative in both], while in other procedures, a single response in either initial link results in entrance into that terminal link. Both arrangements have advantages and disadvantages (Mazur, 1987). Although delays in the initial links (i.e., the duration of the choice period) can affect choice proportions in concurrent-chains procedures (Fantino, 1969), multiple responses in the initial links allow a more sensitive measure of the relative degree of preference for one terminal link over the other. Single-response requirements in the initial links remove the confounding influence of the time spent in the initial links, but can be less informative about degrees of preference. With multipleresponse requirements in the initial links, preference is assessed by the relative response rates in each initial link. With single-response requirements, preference is assessed by the relative likelihood with which the organism enters into that terminal link (Catania, 1998).

Another choice procedure, known as the adjusting procedure, has been used to study self-control (e.g., Grossbard \& Mazur, 1986) and procrastination (Mazur, 1996, 
1998). In this procedure, two alternatives are presented. One of these is the standard, in which the variable of interest (e.g., reinforcement delay or work requirement magnitude) is held constant across trials. In the other alternative, labeled the adjusting alternative, some variable is manipulated across trials, based on the organism's responses during the previous trial. For example, if the standard alternative is chosen, the delay to reinforcement or the work magnitude may be decreased on the adjusting alternative for the next set of trials. If the adjusting alternative is chosen, the delay to reinforcement or the work magnitude may be increased on that alternative on the next set of trials. Using such a titrating procedure, an "indifference point" can be reached - a point at which both alternatives are chosen about equally often.

\section{Delay-of-Reinforcement Effects}

Preparations used to study procrastination, as well as those used to study selfcontrol, generally involve two alternatives differing in their delays to some environmental consequence (Mazur, 1996; Rachlin \& Green, 1972). These delays have been shown to affect choice. Chung and Herrnstein (1967) used a concurrent schedule to measure choice as a function of reinforcement delay. Pigeons' keypecks were reinforced on VI 1-min schedules on two concurrently available keys. After responding was stable and approximately equally distributed across both keys, reinforcement was delayed by $8 \mathrm{~s}$ on one key (delay signaled by a blackout), and was varied between 1 and $30 \mathrm{~s}$ across sessions on the other key. Relative rates of responding on the key with the standard delay were a function of both the delay on that key (which varied across conditions) and the relative delay on the key correlated with the varied delay to reinforcement. Relative rates of responding decreased monotonically with increasing delays to reinforcement. The authors concluded that the relative immediacy of reinforcement influences choice, and that the relative frequency of responding on one alternative in a two-key situation matches the relative immediacy of reinforcement on that alternative. More recent studies of choice between differing delays to reinforcement have demonstrated that, although pigeons' choice proportions do not match delays to reinforcement as asserted by Chung $\&$ Herrnstein, they are invariably higher for the less-delayed reinforcer (Gentry \& Marr, 1980; Omino \& Ito, 1993; Williams \& Fantino, 1978).

\section{Self-Control with Positive Reinforcers}

In typical self-control preparations, it is not only the delay to the positive reinforcer or aversive event that differs in the two alternatives, but also the magnitude of the consequence. That is, self-control is demonstrated when the later, but larger reinforcer is chosen over the sooner, but smaller one. In a study by Ainslie (1974), pigeons either pecked a key, resulting in a smaller, immediate reinforcer, or did not peck the key, resulting in a larger, delayed reinforcer. In addition, pigeons could make a commitment response earlier in the trial, resulting in subsequent access to the larger, delayed reinforcer only. In this procedure, the key was transilluminated with green light for $7.5 \mathrm{~s}$. If the pigeon did not peck the green key, it was darkened for $4.5 \mathrm{~s}$, then transilluminated with red light for $3 \mathrm{~s}$. If the key was not pecked again while it was red, it was darkened and a 4-s reinforcer was delivered. Pecks on the red key resulted in immediate 2-s access to grain. In some conditions, pecks on the green key served as commitment responses, in that they made the 4-s reinforcer available at the end of the 
trial, while the option to obtain the immediate reinforcer was not available. When presented with the red key, all subjects across all conditions pecked it on at least $95 \%$ of the trials. Responding on the green key earlier in the trial was maintained on $50-90 \%$ of the trials when it resulted in commitment to the larger, later reinforcer, but was not maintained in conditions where it did not prevent presentation of the red key (and thus, immediate reinforcement). These findings were interpreted as indicating impulsivity at the point at which the red key was available, and impulse control when commitment responses on the green key were made available.

In a concurrent-chains procedure, Rachlin and Green (1972) manipulated the delay between the commitment response and the availability of either the smaller, immediate or larger, delayed reinforcer. In free-choice trials, pigeons were exposed to two white keys. Pecks could be distributed in any manner on the two keys, but the $25^{\text {th }}$ peck on either key produced the terminal link on that key. Ten forced-choice trials occurred at the beginning of each session to ensure exposure to the contingencies on both keys. During these trials, only one key was available in the initial links, and pecks to the other key had no scheduled effects. The terminal links on both keys began with a delay, which was identical in both terminal links, but was varied across conditions. In the terminal link on the right key, the delay terminated with the transillumination of both keys, one red and one green. A peck on the green key resulted in a 4-s delay followed by 4-s access to grain. A peck on the red key resulted in immediate 2-s access to grain, followed by a 6-s blackout that terminated the trial. In the terminal link on the left key, the delay was followed by illumination of only the green key, and access to only the larger, delayed reinforcer.

Subjects in this procedure, when exposed to both the red and green keys, consistently chose the red key, resulting in the immediate reinforcer. This almostexclusive choice of the smaller, sooner reinforcer developed within the first session, and was evident on at least $95 \%$ of the trials. Of particular interest was the response rate on each of the two keys in the initial links. As the delays in the terminal links increased, response rates tended to increase on the left key, leading to the delayed 4-s reinforcer. In fact, relative response rates indicated a reversal of preference from the right to the left key with increasing delays. This can be interpreted as increased preference for the larger, later reinforcer, because pigeons exposed to both options in the terminal link of the right key virtually always chose the smaller, sooner reinforcer.

Responses on the left key in this procedure were interpreted as commitment responses, because they guaranteed access to the larger reinforcer by prohibiting the choice of the smaller, immediate reinforcer. The reversal of preference was explained by a form of the matching law presented by Baum and Rachlin (1969), which states that the value of two reward alternatives is a function of the product of the ratio of the two reinforcer amounts and the inverse ratio of the two delays to reinforcement. With equal, increasing delays between the choice point and the reinforcers in both alternatives, the value of the larger, later reinforcer will increase relative to the smaller, sooner reinforcer, leading to increased preference for that alternative. Other researchers have examined preference reversal in self-control choice situations as a function of increasing delays 
between the choice point and reinforcer delivery and have found similar reversals of preference with increasing delays (e.g., Green, Fisher, Perlow, \& Sherman, 1981).

\section{Self-Control with Aversive Events}

Several researchers have examined self-control involving aversive events. In these situations, self-control is demonstrated when the smaller, sooner aversive event is chosen over the larger, later aversive event. As with delays to positive reinforcement, delays to shock have been found to affect responding. Hineline (1970) found that rats pressed a lever when it delayed a shock by $8 \mathrm{~s}$, although responding had no effect on overall shock frequency. Moreover, Gardner and Lewis (1976) found that, not only did delaying shock maintain responding, but rats continued to respond to delay shock when responding resulted in a $100 \%$ increase in overall shock frequency. In this procedure, a variable-time (VT) 30-s schedule of shock delivery was in effect in what was labeled the imposed condition. A lever press in this condition resulted in access to an alternate condition, which consisted of either a delay followed by a series of shocks, or a richer VT schedule (for control groups). Both the delay/shock and control conditions contained twice the shock frequency of the imposed condition. In other conditions of the experiment, the alternate condition contained either 1.5 or 3 times the shock frequency as in the imposed condition. In the group for which the alternate condition contained twice as much shock as in the imposed condition, each rat spent between 60 and $80 \%$ of the session time in that alternate condition. Even when the alternate condition produced three times the overall shock frequency, one of three rats in this group spent approximately $80 \%$ of its time in this condition. These findings indicate that delaying shock can result in the acquisition and maintenance of responding even when the consequence is an increase in overall shock frequency.

If manipulating delay parameters in situations involving aversive consequences has the same effect on self-control as in situations with positive reinforcers, then selfcontrol might be considered to function analogously in both situations. Deluty (1978; Experiment 3) used a concurrent-chains procedure with rats to determine whether delays to shock would function in the same way as delays to positive reinforcers. In one terminal link, a shock of 1-s duration was delivered after a short delay. In the other terminal link, a shock of 2-s duration was delivered after a longer delay. Increasing the delays to shock in both terminal links, with a constant absolute difference of $10 \mathrm{~s}$ between delay durations, resulted in a preference reversal from impulsiveness to self-control. Deluty (1978) interpreted these findings in light of the Rachlin-Baum (1969) model described above. This model can be applied to aversive events, by substituting the small reinforcer with the small punisher, and the positive value of the reinforcer with the degree of aversiveness of the punisher. Therefore, at a choice point closer in time to the delivery of the aversive event, the organism is more likely to choose the larger, delayed punisher. At a point in time more distal to delivery, however, the aversiveness of the smaller, more immediate punisher is decreased, so it will be chosen.

The Rachlin-Baum (1969) model makes predictions for commitment responses as well. If the organism can make a commitment response in advance, the model predicts that it will do so. The probability of such a response should increase with increasing time 
between that choice and delivery of the consequence. This result was obtained by Rachlin and Green (1972) with pigeons choosing between positive reinforcers, and by Deluty, Whitehouse, Mellitz, and Hineline (1983) with rats choosing between aversive events. In the Deluty et al. study, rats could make a commitment response that omitted a later choice between a small, immediate shock and a larger, delayed shock. That is, by responding early in the trial, subjects committed to receiving a 0.5 -s shock later. If they did not respond, they later were offered the choice between an immediate 0.5 -s shock and a delayed 5-s shock. As in the Rachlin and Green (1972) study, when the choices were available simultaneously, subjects showed little self-control. Only one of the three subjects consistently chose the smaller, more immediate shock. The proportion of commitment responses made earlier in the trial, however, was much higher for each subject than its proportion of self-control responses when given both options simultaneously. In addition, the proportion of these commitment responses increased systematically for each subject as the delay to the later choice period increased. Deluty et al. concluded that self-control choices involving aversive events function analogously to those with positively reinforcing consequences, in that impulsivity is demonstrated at the choice point, but self-control is demonstrated when the opportunity to make a commitment response is made available in advance. In addition, preference for the smaller, more immediate punisher increases with increasing delays in a manner analogous to the increasing preference for larger, later positive reinforcers.

Green and Rachlin (1996) paired punishing and positively reinforcing consequences in a self-control procedure. In a concurrent-chains schedule, one terminal link led to a choice between a smaller, sooner reinforcer and a larger, later reinforcer. The other terminal link led to a choice between a smaller, sooner reinforcer followed by a punisher (extended blackout) and a larger, later reinforcer. The values for these different consequences had been determined in advance such that, for each pigeon, there was a strong preference for the smaller, sooner reinforcer over the larger, later reinforcer, and also a strong preference for the larger, later reinforcer over the smaller, sooner reinforcer combined with punishment. This method assured that the choice of one terminal link resulted in only one consequence, because once subjects reached the choice point in that terminal link, they almost always chose that particular outcome.

The delay between the choice periods in the initial and terminal links was manipulated across sessions. When subjects chose the terminal link leading to the choice between the smaller, sooner reinforcer and the larger, later reinforcer, all subjects chose the smaller, sooner reinforcer almost exclusively. When subjects chose the terminal link leading to the choice between the smaller, sooner reinforcer followed by punishment and the larger, later reinforcer, most chose the larger, later reinforcer on the majority of trials. This is not surprising due to the manipulations of the parameters of these consequences earlier in the experiment to ensure these choices. The primary interest in this experiment was the proportion of commitment responses in the initial links of the chain. A commitment response was a choice of the punished terminal link, because this terminal link virtually guaranteed a choice of the larger, later reinforcer. As the absolute terminal link delays increased, preference increased for the punished terminal link. This procedure also allowed subjects to break their commitment by choosing the smaller, sooner 
reinforcer combined with punishment over the larger, later reinforcer when they reached that choice point. In fact, this commitment was frequently broken because pigeons would choose the punished terminal link but then would choose the smaller, sooner reinforcer followed by blackout over the larger, later reinforcer. This finding supports the notion that the larger, later reinforcer may be preferred at a point more temporally distal from the consequences, but that preference for the smaller, sooner reinforcer increases with decreasing delays to its onset.

\section{Work Requirements as Aversive Events}

In the studies discussed thus far, the aversive outcome has been either shock or, in the case of Green and Rachlin (1996), blackout. In the laboratory study of procrastination, the consequences have been work requirements, often of differing magnitudes (Mazur, 1996, 1998). There is some evidence to indicate that work requirements can function as aversive events. Appel (1963) arranged two response keys such that pigeons could receive food reinforcement on the left key on a fixed-ratio (FR) schedule, the value of which varied across sessions from FR 80 to FR 240. In addition, they could respond on the right key to produce a stimulus change and timeout from the FR requirement. A second response on the right key restored the original stimulus conditions and the FR requirement on the left key. Pigeons under these conditions did terminate the FR requirement, and the number of these responses increased with increasing FR values. Right-key responses in this procedure served as escape responses from the stimuli associated with the FR schedule on the left key. Because this escape behavior was maintained, and because the number of these responses increased with increasingly lean FR schedules, one interpretation is that the work requirement of the FR schedule was aversive.

In spite of some findings indicating that pigeons are indifferent between simple delays to reinforcement and delays with some required responding (Neuringer, 1969; Omino \& Ito, 1993), there is other evidence indicating that the responding required in FR schedules can be aversive in certain situations. In a study by Grossbard and Mazur (1986), pigeons chose simple delays (i.e., FT schedules) over FR schedules with the same average times between the choice response and reinforcement. These authors suggested that keypecking, which occurred in the FR schedule, was relatively more aversive than delay behavior (e.g., pacing, standing still) which occurred during FT schedules, in which the keylight was darkened and no key peck was required for reinforcement. Using a concurrent-chains schedule, Fantino (1968) found that pigeons consistently preferred a fixed-interval (FI) schedule to a differential-reinforcement-of-high-rate (DRH) schedule, even though both schedules resulted in the same probability and duration of reinforcement. Although Fantino (1968) interpreted these results in terms of the strength of the conditioned reinforcers associated with the different schedules, it also could be argued that the work requirement in the DRH schedule was aversive relative to the FI schedule, in which only one response is required to produce reinforcement. It seems evident from these findings that pigeons are not always indifferent between simple delays and required rates of responding, and that the required rates, as in an FR schedule, can be aversive, even though their completion results in reinforcement. 


\section{The Study of Procrastination}

If FR requirements can serve as aversive events, then they should function in a manner similar to other aversive events in self-control situations. Specifically with respect to a study of procrastination, larger, later work requirements should be chosen over smaller, sooner work requirements. This prediction was tested by Mazur (1996) in three experiments in which FR response requirements followed some delay. Pigeons consistently preferred delayed FR requirements, even when the value of the delayed FR schedule was four times that of the FR schedule with an earlier onset.

In Experiment 1, Mazur (1996) employed an adjusting-ratio procedure to obtain indifference points between two FR requirements delayed by some amount. The delays to the FR schedule onset varied across conditions, but were constant within a condition. In some conditions, choice of the standard key resulted in a 6-s delay, followed by the required completion of an FR 5 schedule and a 34-s delay. During the delays before and after the work requirement, a VT 20-s schedule was in effect. Completion of the work requirement did not result in an immediate reinforcer, but simply allowed the VT schedule to resume for the remainder of the trial. Choice of the adjusting key led to a 20-s delay with the VT 20-s schedule in effect, followed by the required completion of an FR schedule, the value of which increased or decreased across trials, depending on a subject's choices. Here as well, completion of the FR requirement did not produce a reinforcer, but simply allowed the VT schedule to resume. An indifference point was reached when subjects consistently chose each alternative equally often. As the delay to the onset of the adjusting ratio increased, the mean adjusting ratio increased. For example, pigeons were indifferent between the standard FR 5 following the 6-s delay and an FR 20 following a 25-s delay. Although there was more within-subject variability than is usually found with this procedure when positive reinforcement is involved, the adjusting ratio size consistently increased with increasing delays to its onset. Mazur described these findings in terms of procrastination as defined above.

One problem in Mazur's (1996) Experiment 1 was that there were two advantages of choosing the more delayed work requirement, unrelated to an analysis in terms of selfcontrol. Because the VT 20-s schedule was in effect for only $6 \mathrm{~s}$ in the standard alternative, the chances of receiving a reinforcer during that time were not great. Thus, choices of the adjusting alternative with the longer initial VT-schedule segment may have been reinforced by the higher probability in that alternative of receiving an early reinforcer. Another potential problem stemmed from the fact that the FR requirements interrupted periods of free food delivery. Therefore, the FR requirements may have served as timeouts from positive reinforcement. If this were the case, then subjects' choices of the adjusting alternative could be explained as choices of a larger, more delayed timeout over a smaller, more immediate timeout from positive reinforcement.

To control for some of the potential confounds in Experiment 1, Mazur (1996; Experiment 2) substituted simple delays (i.e., periods with keylights darkened and only the houselight illuminated) for the VT segments that preceded and followed the work requirements. Pigeons chose between an FR 8 wherein the onset was delayed by $2 \mathrm{~s}$ and an FR 8 wherein the onset was delayed by $15 \mathrm{~s}$. The adjusting procedure was not used, 
and both the FR values and the delays to the onset of the work requirements in both terminal links were held constant. The only reinforcer delivered in these trials was a 4-s food presentation at the end of the terminal link. Pigeons in this procedure chose the more-delayed work requirement approximately $75 \%$ of the time. Because only one reinforcer was delivered in both alternatives at the end of the trial, with the time between its delivery and the choice response held constant, preference cannot be attributed to the higher probability of early reinforcement in the delayed alternative. In addition, because simple delays were used rather than VT schedules, it appeared that preference was not due to the later onset of a timeout from positive reinforcement.

With an adjusting-delay procedure, Mazur (1998) found similar results with FI schedules. On the standard key, an FI 5-s requirement followed a 10-s delay and interrupted periods of free food delivery on a VT 20-s schedule. On the adjusting key, an FI 15-s requirement followed an adjusting delay, also interrupting periods with the VT 20-s schedule in effect. The indifference points were similar to those obtained with FR requirements, in that the adjusting delay increased with increasing standard delays. For example, averaging across birds, the FI 5-s requirement delayed by $10 \mathrm{~s}$ was equally preferred to an FI 15-s requirement delayed by about $33 \mathrm{~s}$.

The results from these experiments (Mazur, 1996, 1998) were taken as evidence of procrastination. Procrastination was argued to function in a manner analogous to selfcontrol choices involving aversive events. That is, pigeons chose the larger, later aversive event (i.e., work requirement) over the smaller, sooner aversive event. Mazur argued that these choices were due to the decreasing effect of a consequence on behavior, as the delay to that consequence increases.

Statement of the Problem

Procrastination has been defined within behavioral psychology as the choice of a larger, more delayed work requirement over a smaller, more immediate work requirement (Mazur, 1996, 1998). Defined in this way, procrastination choices are analogous to selfcontrol choices involving aversive events. Self-control has been described in terms of choices between smaller, sooner reinforcers and larger, more delayed reinforcers (Ainslie, 1974; Rachlin \& Green, 1972). Self-control is demonstrated if the larger, later reinforcer is chosen. With respect to aversive events, the self-control choices are between smaller, sooner aversive events and larger, more delayed aversive events (Deluty, 1978; Rachlin, 1974). In these situations, self-control is demonstrated if the smaller, sooner aversive event is chosen.

Several empirical parallels exist between self-control choices involving positively reinforcing and aversive events. Rachlin and Green (1972) found that pigeons' choice proportions for an immediate 2-s reinforcer over a 4-s reinforcer delayed by $4 \mathrm{~s}$ were never less than $95 \%$ for any subject across trials. When given the opportunity to respond in advance, however, resulting in only the 4-s delayed reinforcer without the option to choose the immediate one, pigeons did make this response. In addition, these commitment responses increased with increasing absolute delays to the consequences. In an analogous situation involving aversive events, Deluty et al. (1983) found that rats 
often chose a 5 -s shock delayed by 5 s over a 0.5 -s immediate shock. Responding that resulted in commitment to the smaller, more immediate shock, however, was acquired and maintained. This preference for the smaller, more immediate shock increased with increasing absolute delays to the consequences.

The parallel effects just described can be explained by the argument that the effect of a particular consequence decreases with increasing delays to its onset. If this is the case, then we might expect that the smaller, more immediate reinforcer will be chosen, although such a choice comes at the cost of a larger reinforcer later. Similarly, such a view allows for the prediction that the more delayed punisher will be chosen because, although a choice of the more immediate punisher would result in the shock of shorter duration, the effect of the larger punisher is weakened by the delay to its onset.

Several lines of evidence have indicated that work requirements, such as are found in FR schedules, can serve as aversive events. Appel (1963) found that responding was maintained in pigeons when it resulted in a timeout from an FR schedule or from an elimination of the stimuli correlated with the FR schedule. In addition, the number of these escape responses increased with increasingly lean FR schedules. Grossbard and Mazur (1986) found that pigeons preferred a fixed-time (FT) schedule to an FR schedule with the same average time to reinforcement, and Fantino (1968) found that pigeons preferred an FI schedule, which requires only one response for reinforcement, to a DRH schedule, which imposes some required rate of responding.

If an FR schedule can function as an aversive event, then it should have effects on self-control choices analogous to those found with other aversive events. That is, when given the choice between a smaller, more immediate work requirement and a larger, more delayed work requirement, the larger, later one should be preferred. Mazur (1996) used an adjusting procedure with pigeons to measure preference for work requirements that differed in their magnitude and in the delay to their onset. Pigeons preferred an FR schedule delayed by only a few seconds, even when this entailed a fourfold increase in the response requirement. This preference obtained whether the FR requirements interrupted periods of free food delivery on VT schedules, or when they were preceded and followed by simple delays, with only one reinforcer delivered at the end of the trial.

In two of three experiments, Mazur (1996) employed an adjusting-ratio procedure. This procedure has been argued to have several advantages over other procedures for assessing preference, such as concurrent-chains schedules (Mazur, 1987). The adjusting procedure produced more variable results, however, than is usually found in self-control studies involving positive reinforcers (Mazur, 1998). In one experiment, Mazur (1996; Experiment 2) employed a concurrent-chains schedule in which a single peck on a center key resulted in transillumination of two side keys - one orange and one blue. A peck on the orange key resulted in a 2-s delay with only the houselight illuminated, followed by the re-illumination of the orange key, on which an FR 8 schedule was in effect. Completion of the FR 8 schedule resulted in a 15-s delay with only the houselight illuminated. A 4-s reinforcer was delivered at the end of the 15-s delay, thus ending the trial. A peck on the blue key led to a 15-s delay, followed by re- 
illumination of the blue key with an FR 8 schedule in effect on that key. Completion of an FR 8 resulted in a 2-s delay followed by the 4-s reinforcer. The key colors then were reversed. Pigeons preferred the more delayed work requirement on approximately $75 \%$ of the trials in both conditions.

One interpretation of these findings could be that the preference was due, not to the reinforcing effectiveness of the longer delay to the onset of the FR schedule, but to the fact that reinforcement followed completion of the delayed work requirement much more closely than the early-onset work requirement. That is, when the onset of the work requirement was delayed by $2 \mathrm{~s}$, its completion was followed by reinforcement $15 \mathrm{~s}$ later. When the onset of the work requirement was delayed $15 \mathrm{~s}$, its completion was followed by reinforcement only $2 \mathrm{~s}$ later. Because delay of reinforcement affects choice (Chung \& Herrnstein, 1967), it could be argued that the delayed work requirement was preferred because of its proximity to reinforcement.

The present experiment was designed to examine more closely this relation between delays to reinforcement and to work requirement onset. As in Mazur's (1996; Experiment 2) procedure, the terminal links of each chain consisted of either a short or long delay, followed by required completion of identical FR schedules. Unlike Mazur's procedure, however, reinforcement followed immediately upon completion of the FR schedules in Phase 1 of the current experiment. Terminal-link length was held constant for both alternatives, and reinforcement was followed by a delay for the duration of this length. If procrastination choices are due to the reinforcing efficacy of longer delays to the onset of the work requirement, we would expect preference for the later work requirement. If choices are due to the closer temporal proximity of the work requirement to reinforcement, however, we would expect indifference between the two alternatives, because reinforcement immediately follows work requirement completion in both terminal links. Alternatively, it could be argued that preference would develop for the work requirement with the earlier onset, because reinforcement occurs earlier in this alternative relative to the choice point, and it has been shown that shorter delays to reinforcement are preferred over longer delays (Gentry \& Marr, 1980; Omino, 1993). From this position, it may be argued that the reinforcing effectiveness of a less-delayed reinforcer will override the reinforcing effectiveness of a more-delayed work requirement, resulting in preference for the less-delayed reinforcer (and, hence, lessdelayed work requirement). In Phase 2, a delay to reinforcement was added, following completion of the earlier-onset work requirement, to assess the effects on choice of differing delays to the work requirements when only the later-onset work requirement produces reinforcement immediately upon its completion.

Subjects

\section{Method}

Four experimentally naïve, male White Carneau pigeons, each maintained at $80 \%$ of its free-feeding weight, were used. Subjects were housed individually, with free access to water and grit in their homecages. 
Apparatus

A standard three-key operant chamber was used. The chamber was located in a sound-attenuating enclosure, with a ventilation fan to mask extraneous noises. The work area of the chamber measured $32 \mathrm{~cm}$ long by $30 \mathrm{~cm}$ high by $30 \mathrm{~cm}$ wide. The center key was $2 \mathrm{~cm}$ in diameter and was centered on an aluminum work panel, $22.5 \mathrm{~cm}$ from the floor. This key was inoperative during the present experiment. Two side keys were on the right and left sides of the work panel, each located $5 \mathrm{~cm}$ from the center key. Each of these keys could be transilluminated by green or red light and required a force of $0.15 \mathrm{~N}$ to operate. The food hopper was accessible through a $5-\mathrm{cm}^{2}$ feeder aperture. The aperture was centered on the aluminum panel directly below the center key and $8 \mathrm{~cm}$ above the floor. When activated, the hopper was raised into the aperture, which was illuminated by a white light during reinforcement. Houselights, located at the center of the chamber ceiling, were illuminated by white, green, or red lights at different times in the experiment as described below. A computer located in an adjacent room operated Med-PC $\subset$ software that controlled the experiment and recorded the data.

Procedure

Preliminary Training. Keypecking was established using a modified autoshaping procedure (Brown \& Jenkins, 1968). After an intertrial interval of either 80, 90, or $100 \mathrm{~s}$, one of the two side keys, selected randomly, was illuminated by either green or red light. If no keypeck occurred, the keylight was extinguished after $6 \mathrm{~s}$, and was followed immediately by 4-s access to grain. Each peck to the illuminated key darkened it and produced immediate 4-s access to grain.

After keypecking was established on both red and green side keys, an FR 1 schedule was effected. During these sessions, one of the two side keys was randomly illuminated (i.e., left key red, left key green, right key red, or right key green), along with either the color-correlated or white houselight. A peck to the illuminated key produced 3 -s access to grain. Across sessions, the response requirement on each key was increased from FR 1 to FR 40. Each session ended after 10 reinforcers were obtained on each of the four possible keylights. Two subjects (9956 and 8950) were exposed to nine sessions of this training and two subjects (9911 and 9922) were exposed to 15 sessions.

Phase 1. A concurrent-chains schedule was employed. Two independent and mutually exclusive VI 15-s schedules operated in the initial links on the two side keys, with a 3-s changeover delay (COD) in effect. The VI 15-s schedules were comprised of 20 intervals with a mean of 15 s (cf., Fleshler \& Hoffman, 1960). On each trial, one interval was randomly chosen for each of the keys, and access to the terminal links was contingent upon the first keypeck following the lapse of the chosen interval on that key, as well as the lapse of the COD. The COD was programmed such that a peck on either key in the initial links started a 3-s timer, during which time pecks to the other key did not produce access to the terminal link on that key.

These keys were illuminated either red or green, with the color position on each trial determined randomly. During the initial links, the houselight was white. To ensure equal exposure to both terminal links, trials were grouped into blocks of four. In each 
trial, access to only one terminal link was programmed such that in a block of four trials, two allowed access to the terminal link on the red key and two allowed access to the terminal link on the green key.

In Conditions 1 and 3, the terminal link on the red key consisted of a 5-s delay, during which the keylights were darkened and the houselight was red. After $5 \mathrm{~s}$, the red key was re-illuminated, and remained so until the subject completed an FR-20 response requirement. Completion of an FR 20 resulted in 3-s access to grain. Reinforcement was followed by a delay with darkened keylights and red houselight, which continued until $45 \mathrm{~s}$ had passed since the onset of the terminal link. The terminal link on the green key resulted in a 20-s delay, during which all keys were darkened and the houselight was green. After $20 \mathrm{~s}$, the green key was re-illuminated, and remained so until the subject completed an FR-20 response requirement. Completion of the FR 20 resulted in 3-S access to grain, followed by a delay with darkened keylights and green houselight, which continued until $45 \mathrm{~s}$ had passed since the onset of the terminal link. If the response requirement was not completed within $45 \mathrm{~s}$ in either terminal link, the trial ended without reinforcement, and the next trial began. This occasionally occurred, but was frequent enough with one subject (9911) that the response requirement was changed to an FR 5 for the remainder of the experiment. Conditions 2 and 3 consisted of color reversals, in which the terminal link conditions for the two key colors were reversed.

Conditions remained in effect for a minimum of 20 sessions, and until the choice proportion on the red key in each of the last five sessions was not the highest or lowest of the condition (cf., Mazur, 1996). Additional stability criteria were determined by grouping the last nine sessions into three-session blocks. Stability was reached when the choice proportion means in each of the three-session blocks showed no increasing or decreasing trend and did not differ from each other by more than $8 \%$. Preference was assumed if subjects' choice proportions were greater than $50 \%$ at stability in Conditions 1 and 3, and less than $50 \%$ in Condition 2.

Phase 2. The only change in Phase 2 was the addition of a 5-s delay to reinforcement following completion of the early-onset work requirement. In Conditions 1 and 3, the red terminal link contained the early-onset work requirement and in Condition 2, the green terminal link contained the early-onset work requirement. All other parameters were identical to those in Phase 1.

All sessions were conducted 6 days per week. The total number of sessions per condition in both phases is shown in Table 1. All stability criteria were met in less than 34 sessions for each subject in each condition. 
Table 1

Total Number of Sessions per Condition for all Subjects. Conditions 1 and 3 Involved an Earlier-Onset Work Requirement in the Red Terminal Link and Condition 2 Involved an Earlier-Onset Work Requirement in the Green Terminal Link.

\begin{tabular}{ccccc}
\hline Condition & 8950 & $9911^{\frac{\text { Subject }}{2}}$ & 9922 & 9956 \\
\hline Phase 1 & 30 & 28 & 20 & 34 \\
1 & 25 & 34 & 24 & 24 \\
2 & 24 & 25 & 32 & 31 \\
3 & & & & \\
Phase 2 & 20 & $*$ & 20 & 20 \\
1 & 31 & $*$ & 25 & 24 \\
2 & 21 & $*$ & 20 & 20 \\
3 & & &
\end{tabular}

* Subject was not used in Phase 2. 
Results

Initial-link response rates across all conditions of Phase 1 are shown in Figure 1. Although there was a fair amount of overlap for three of the subjects due to side biases, it can be seen that rates on the red key in the initial links were generally higher than rates on the green key when the red key produced access to the early-onset terminal link in Condition 1. These patterns reversed during the color reversal in Condition 2 and were reinstated in Condition 3. Because key color, rather than location, determined terminallink contingencies, no attempts were made to remove the side biases.

Choice proportions were calculated as the number of red-key pecks in the initial links divided by the total number of initial-link pecks. Choice proportions during Phase 1 indicated a preference for the red key during the initial links when it produced access to the terminal link with the early-onset work requirement (see Figure 2). Like initial-link response rates, this preference reversed during the color reversal and was reinstated in Condition 3.

Initial-link response rates and choice proportions in Phase 2 are shown in Figures 3 and 4, respectively. Both of these measures indicated no substantial effect on preference of adding a 5-s delay to reinforcement following completion of the early-onset work requirement. Response rates and choice proportions remained high on the key leading to the terminal link with the early-onset work requirement, and were comparable to those obtained in Phase 1. Response rates and choice proportions were sensitive to the color reversal in Conditions 2 and 3. For Subject 8950, preference did not reverse in the first color reversal in that it remained above 0.50 at stability. Visual inspection of the data, however, indicated that choice proportions decreased in Condition 2 and increased again in Condition 3.

Mean response rates and ranges during the terminal-link work requirements for the last nine sessions of each condition are shown in Table 2. These rates generally were higher during the early-onset work requirement in Phase 1. Rate differences tended to diminish across color reversals, however, and rates were comparable by Condition 3. During Phase 2, rates during the early-onset work requirement, which was now followed by the 5-s delay, dropped initially, and then increased across color reversals. Occasional low rates in the terminal-link work requirements occurred during some sessions, resulting in the failure to obtain the maximum number of reinforcers (i.e., occasional trials ended without reinforcement).

Terminal-link responding was not maintained with Pigeon 9911 during early sessions in Phase 1. The work requirement in both terminal links for this subject was then reduced to FR 5, and all data presented here are representative of sessions with the FR 5 requirements in place. Nonetheless, initial-link response rates remained low throughout Phase 1, and this subject subsequently was dropped from Phase 2. 


\section{Next Page}

Figure 1. Responses per minute on each key during the initial links of Phase 1. Closed symbols represent response rates on the red key, and open symbols represent response rates on the green key. "Early" and "Late" refer to the terminal-link work-requirement onset across conditions. 
Red
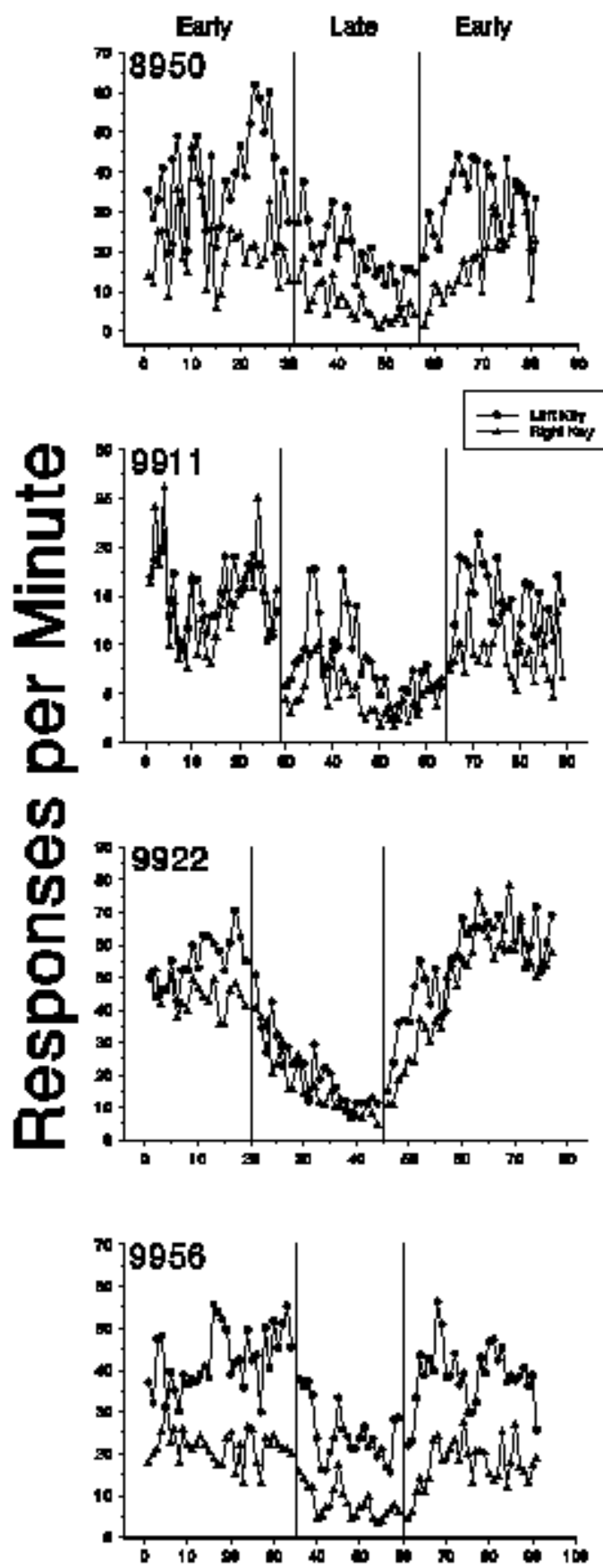

\section{Green}
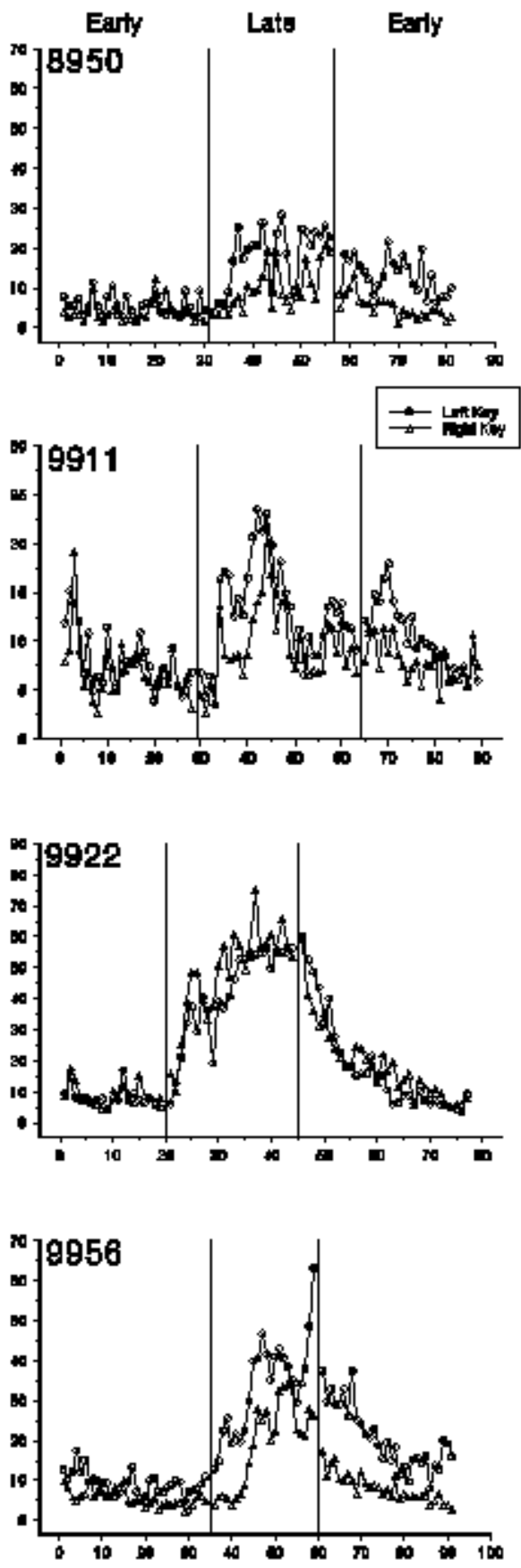

\section{Session}




\section{Next Page}

Figure 2. Choice proportions for the red key during the initial links of Phase 1. "Early" and "Late" refer to the terminal-link work-requirement onset across conditions.

data, however, indicated that choice proportions decreased in Condition 2 and increased again in Condition 3. 


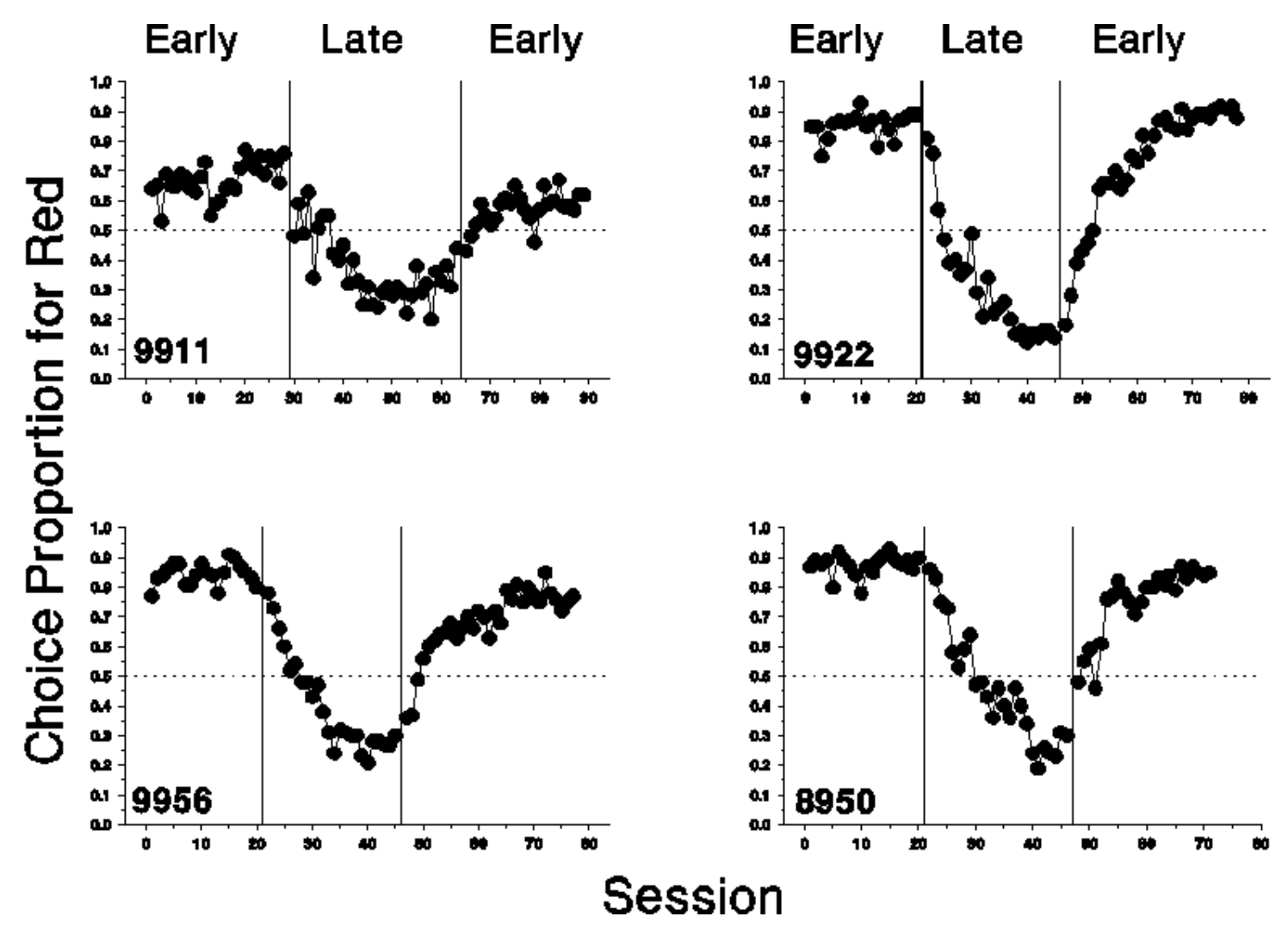




\section{Next Page}

Figure 3. Responses per minute on each key during the initial links of Phase 2. Closed symbols represent response rates on the red key, and open symbols represent response rates on the green key. "Early" and "Late" refer to the terminal-link work-requirement onset across conditions. 
Red
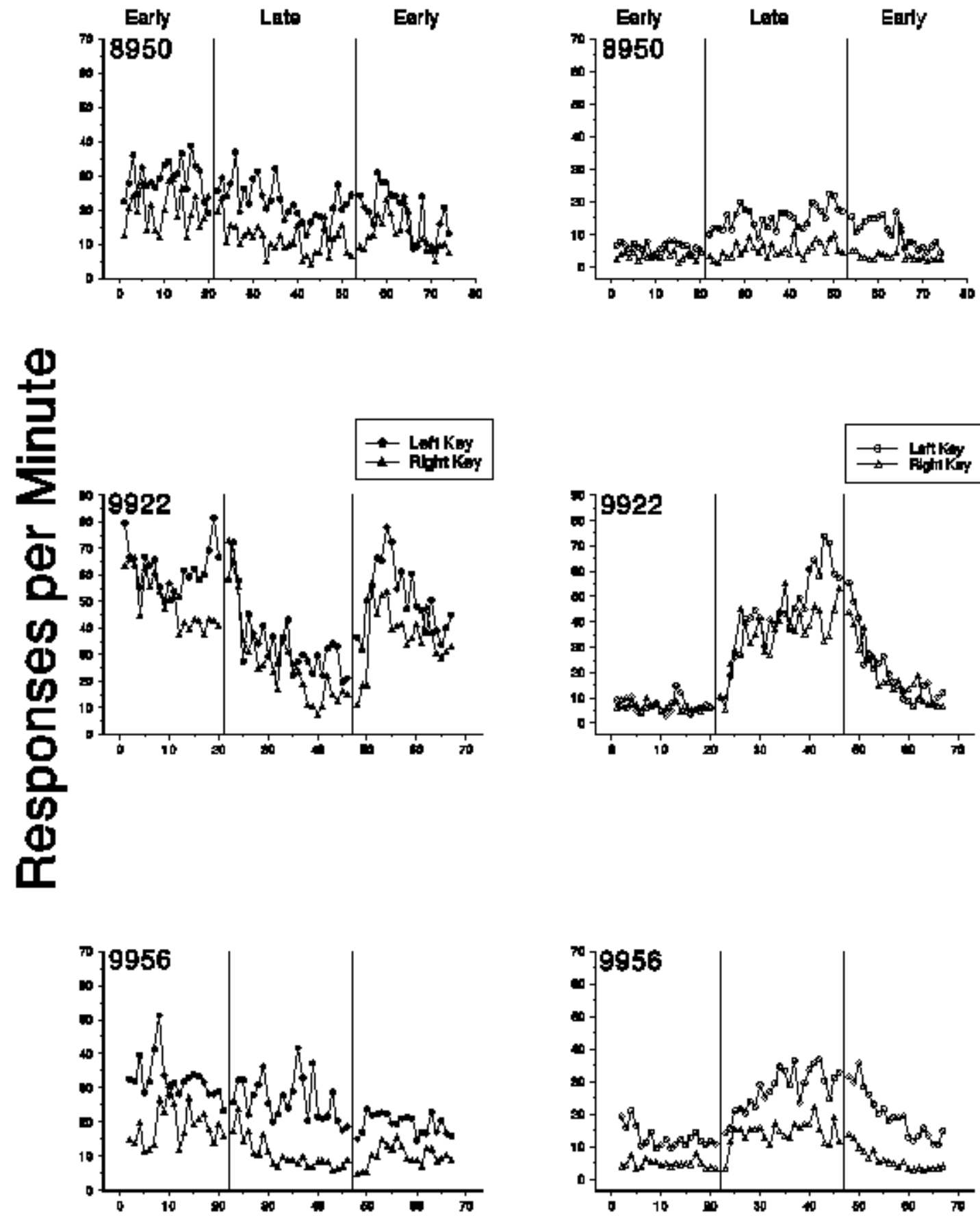

Session
Green
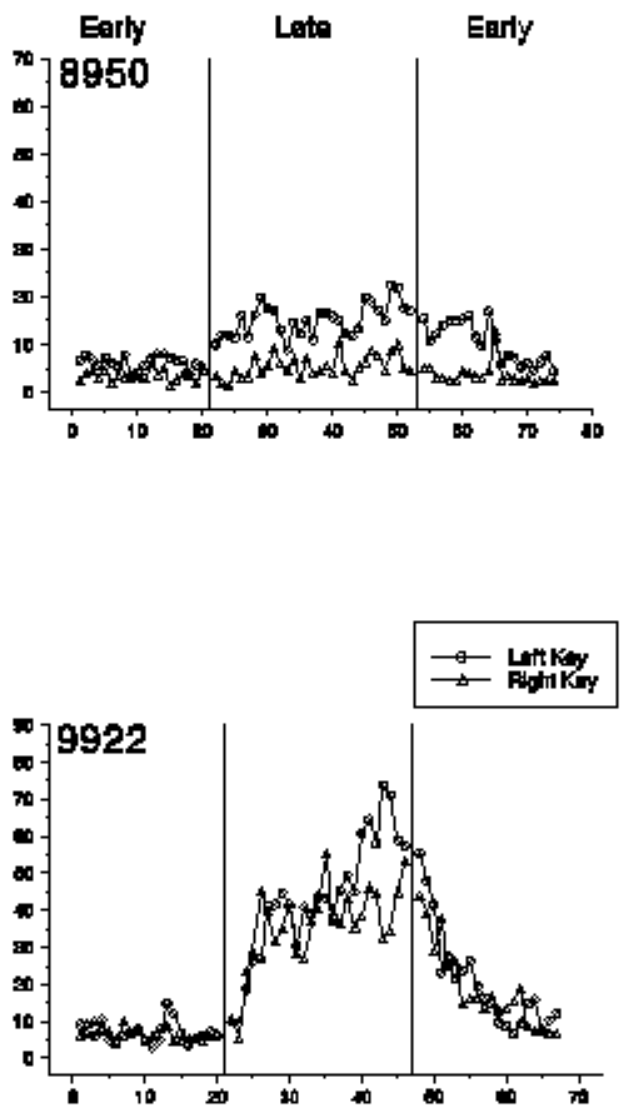


\section{Next Page}

Figure 4. Choice proportions for the red key during the initial links of Phase 2. "Early" and "Late" refer to the terminal-link work-requirement onset across conditions. 

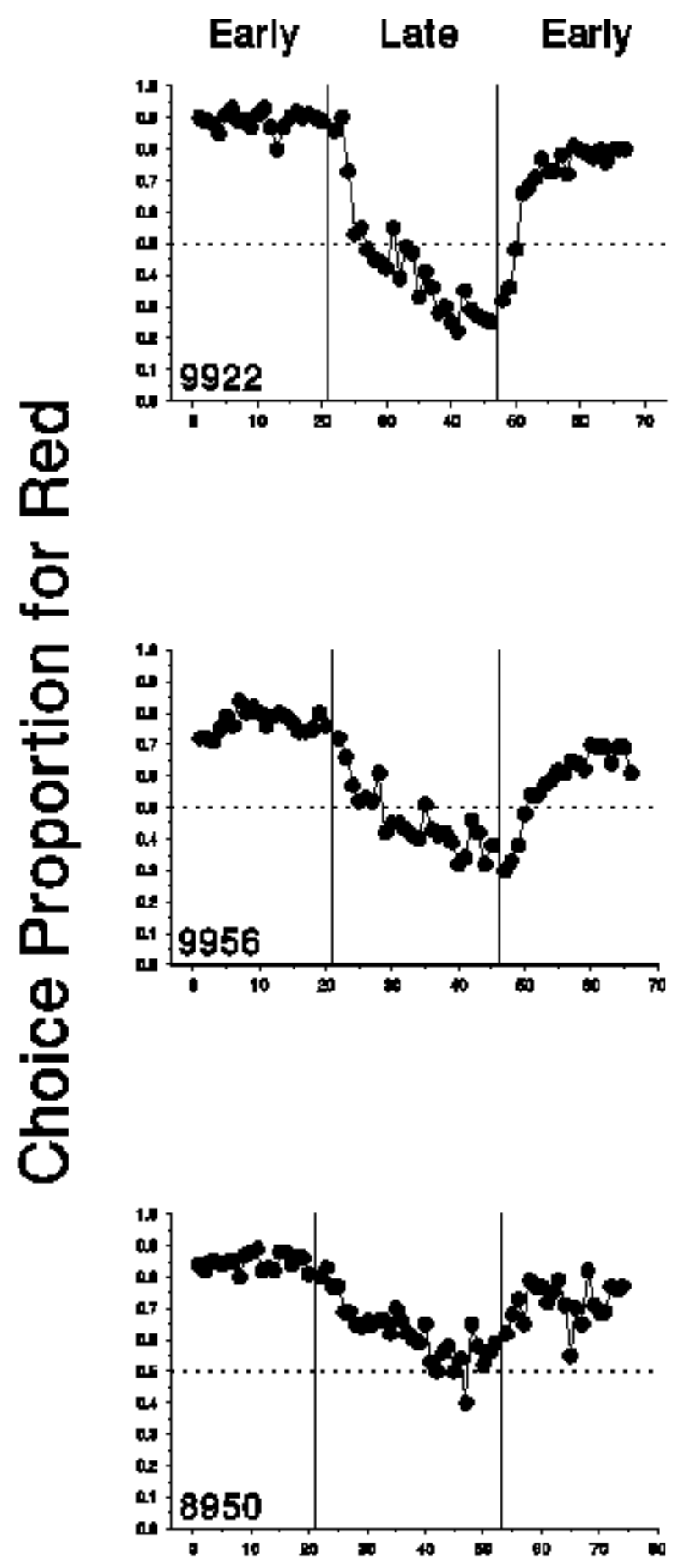

Session 
Mean obtained delays to reinforcement from terminal-link onset and ranges are presented in Table 3. These figures were obtained by calculating terminal-link responses per second and multiplying by the FR requirement (i.e., either 5 or 20 responses). The delay to work requirement onset (i.e., either 5 or $20 \mathrm{~s}$ ) was then added to the time to complete the work requirement. It can be seen that, not only was the overall delay to reinforcement longer in the terminal link with the later-onset work requirement in Phase 1 , but also that it generally remained so in Phase 2.

\section{Discussion}

An earlier-onset work requirement was preferred in situations where it produced reinforcement more temporally proximal to the choice point. This preference occurred even when there was a delay to reinforcement following completion of that work requirement.

It is not surprising that the terminal link with the early-onset work requirement was preferred, because it produced access to a more immediate reinforcer. Delays to reinforcement influence choice in concurrent and concurrent-chains schedules, and choice proportions are a function of both relative and absolute delays to reinforcement (Chung, 1965; Chung \& Herrnstein, 1967; Gentry \& Marr, 1980; Omino \& Ito, 1993; Williams \& Fantino, 1978). Using delays to reinforcement of 0 to 28 s, Chung (1965) found that pigeons' responses on one key of a concurrent schedule were a negative exponential function of increasing delays to reinforcement on that key. In an extension of this research, Chung and Herrnstein (1967) assessed responding in a concurrent schedule with either 8- or 16-s delays to reinforcement on one key, while reinforcement delays were varied between 2 and 30 s on a second, experimental key. Relative response rates on the experimental key decreased as the delay to reinforcement on that key increased. Using a concurrent-chains schedule, Gentry and Marr (1980) assessed choice between two terminal links, in one of which reinforcement was delayed by an interval four times greater than that in the other terminal link, with delays signalled by blackout. Relative frequencies of responding and time allocation on each key in the initial links were almost invariably higher on the key leading to the terminal link with the shorter delay to reinforcement, across several absolute delay values.

In the current experiment, the terminal-link delays to reinforcement involved differential stimuli as well as intervening work requirements. These factors might influence preference between differing delays to reinforcement. Williams and Fantino (1978) found that choice in a concurrent-chains schedule with delays to reinforcement in the terminal links was influenced by the terminal-link stimuli. The terminal links were comprised of FI schedules, one of which was always twice as long as the other. Across conditions, the stimuli in the terminal links were either identical (i.e., uncued with white keylights in both terminal links) or differential (i.e., cued with a unique keylight color in each terminal link). Preferences for the terminal link with the shorter FI schedule were lower in the uncued condition than in the cued condition. Williams and Fantino suggested that the differential terminal-link stimuli made the terminal links more discriminative, thus increasing preference for the shorter delay to reinforcement. This effect was replicated by Omino (1993) and by Omino and Ito (1993) with simple delays 
Table 2

Mean Terminal-Link Response Rates During Early- and Late-Onset Work Requirements of Last Nine Sessions per Condition.

(Ranges are Shown in Parentheses.) Conditions 1 and 3 Involved an Earlier-Onset Work Requirement in the Red Terminal Link and Condition 2 Involved an Earlier-Onset Work Requirement in the Green Terminal Link.

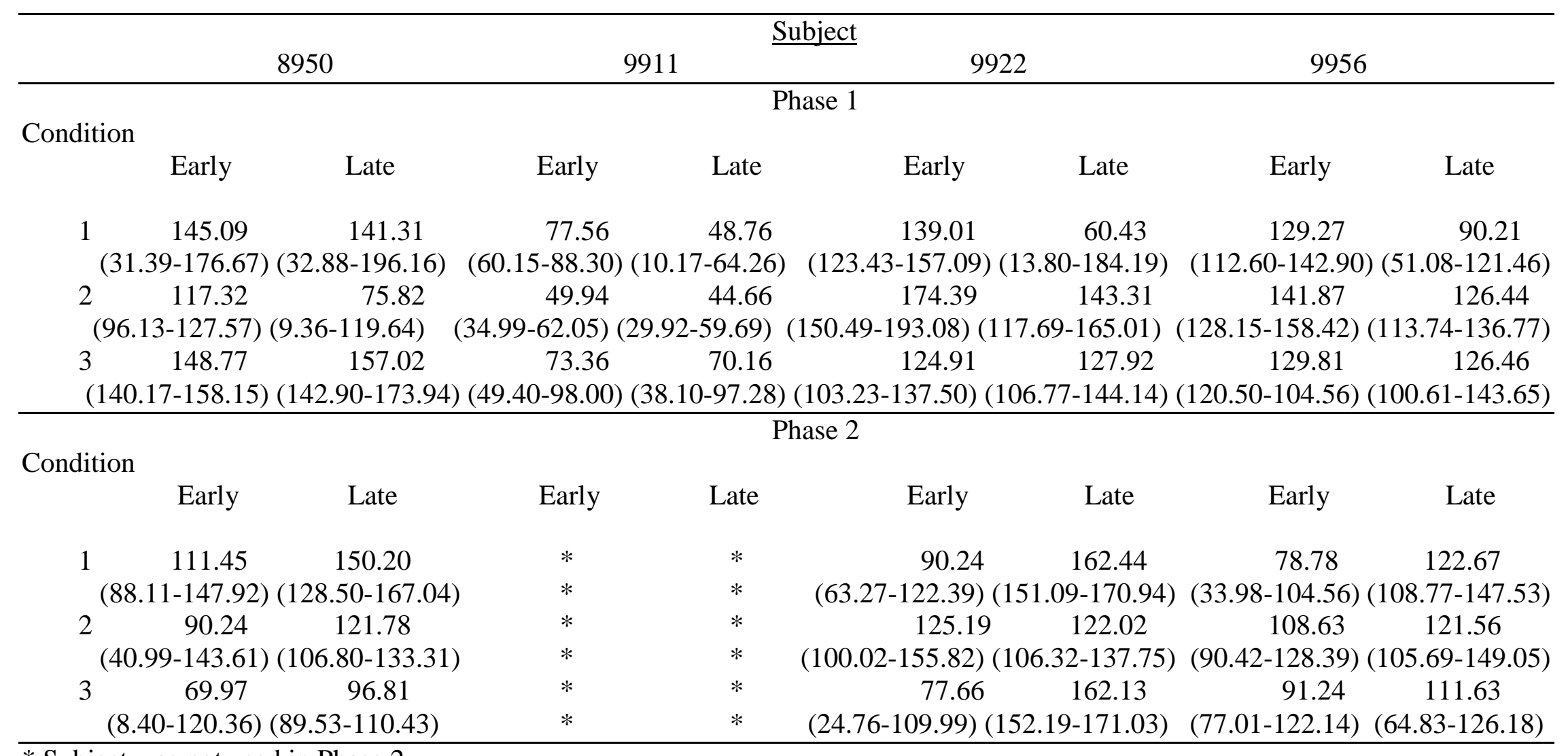

* Subject was not used in Phase 2. 
Table 3

Mean Obtained Delays to Reinforcement (in Seconds) During Terminal Links with Early- and Late-Onset Work Requirements of Last Nine Sessions per Condition. (Ranges are Shown in Parentheses.) Conditions 1 and 3 Involved an Earlier-Onset Work Requirement in the Red Terminal Link and Condition 2 Involved an Earlier-Onset Work Requirement in the Green Terminal Link.

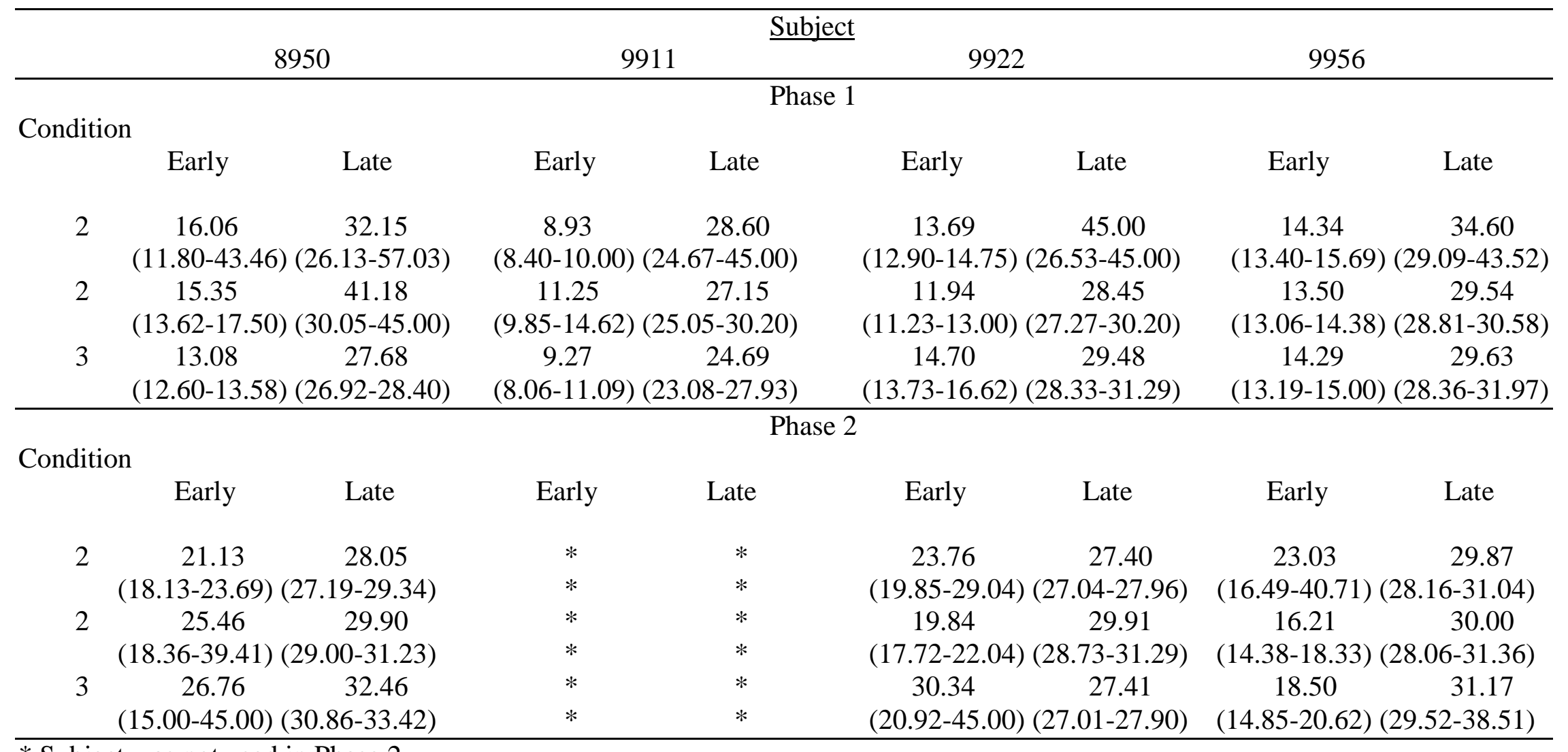

* Subject was not used in Phase 2. 
to reinforcement and with FI schedules in the terminal links. Therefore, the red and green houselights correlated with the two terminal-link delays in the current experiment may have enhanced sensitivity to the differing delays to reinforcement, resulting in the strong preferences obtained.

When work requirements intervene between the choice point and reinforcement, their magnitude or the delay to their onset may still influence choice in situations with delays to reinforcement. Mazur (1996) found that, when delays to reinforcement were held constant from the choice point, the temporal location of the intervening work requirement did influence choice, resulting in procrastination. Conversely, the presence of work requirements per se had little effect on choices between different delays to reinforcement when FT and FI terminal-link schedules were compared (Omino \& Ito, 1993). Further research in the study of procrastination might examine the effects on choice of varying the temporal location of work requirements within either constant or differential temporal intervals between the choice point and reinforcement. Parametric manipulations of the relative overall delays to reinforcement and delays to work requirement onset could reveal delay discounting functions of both in relation to one another.

To make procrastination choices procedurally analogous to self-control choices involving aversive events, the differing delays to reinforcement must be accompanied by different work requirements. In the current experiment, and in that of Mazur (1996; Experiment 2), the work requirements were identical in both terminal links. When one considers procrastination in many everyday situations, however, one observes that often the work requirements are identical in magnitude, whether they are completed early or late. That is, the same magnitude of responding is required, although it may differ in nature when it is completed later, as in when the same amount of work must be completed within a more constricted time frame. Further research in the area of procrastination might examine preferences between early and late work requirements with either a DRH or limited-hold contingency in place for later-onset response requirements.

The addition of the delay to reinforcement following early-onset work requirement completion in Phase 2 did not substantially influence preference. A confound remained, however, in that reinforcement onset was still more temporally proximal to the choice point in this terminal link. Therefore, it remains unclear whether these delays influence procrastination choices when reinforcement is equally delayed from the choice point. Although Phases 1 and 2 provided examples of situations in which a later-onset work requirement was not preferred, it seems likely that these choices were controlled primarily by delays to reinforcement from initial-link responding. It can be seen by comparing Figures 2 and 4 that preferences were influenced slightly in Phase 2 in that, for each subject, preferences were closer to 0.5 in Phase 2 than in Phase 1 . The addition of the delay to reinforcement following work requirement completion did not, however, reverse preferences for any of the subjects in Phase 2. The results of Phase 2 demonstrated, therefore, that early-onset work requirements with a 5-s delay to reinforcement following their completion continued to be preferred over later-onset work 
requirements that produced immediate reinforcement. These results tentatively suggest that the procrastination obtained by Mazur (1996; Experiment 2) may have been due to the decreasing effect of work requirements as aversive events with increases in the delay to their onset, rather than to the proximity of reinforcement to work requirement completion.

Another interpretation of the failure to obtain procrastination in the current experiment could be that work requirements are not functionally aversive when pitted against different delays to reinforcement. If this were the case, then the effects of delays to reinforcement easily would override any opposite delay discounting effects of delays to work requirements. There is some evidence indicating that work requirements are not necessarily aversive events. For example, Neuringer (1969), using a concurrent-chains schedule, assessed pigeons' preferences between terminal links containing either an FI schedule or a fixed delay to reinforcement (signalled by blackout) with the overall time to reinforcement held constant. Neuringer obtained a slight but consistent preference (i.e., $55 \%$ across absolute delay values) for the FI schedule, during which keypecking was required, over the fixed delay, during which keypecking was not required and was not obtained. Delays to reinforcement in the terminal links influenced behavior, in that initial-link response rates decreased with increasing absolute delays, but the required responding in the FI schedule did not decrease preference at any delay value. In a second experiment, pigeons chose between an FI 10-s schedule in one terminal link and a fixed delay of either 2 or $20 \mathrm{~s}$ to food delivery in the other terminal link. A second group of subjects chose between a fixed delay of $10 \mathrm{~s}$ to food delivery and either FI 2- or FI 20-s food delivery schedules. Although preference for the terminal link with the 10 -s overall time to reinforcement decreased when the alternative terminal link contained the 20 -s delay to reinforcement, preference was still slightly higher for the FI 10-s schedule relative to the fixed 10-s delay to reinforcement. These findings suggest that the mere presence of a response requirement will not influence preference with comparable delays to reinforcement from the choice point.

Mazur (1998), nonetheless, obtained procrastination using FI schedules with values within the range tested by Neuringer (1969). Mazur used an adjusting-delay procedure, with the FI schedules interrupting periods of response-independent food delivery according to VT schedules. As the standard delay prior to an FI 5-s schedule increased across conditions, the mean adjusting delay prior to an FI 15-s schedule also increased. That is, pigeons' preferences for a particular terminal link were a function of both the delays to work requirement onset and the work requirement magnitudes in such a way that the larger work requirement was chosen only when it was appreciably more delayed than the smaller work requirement. In light of the conflicting results regarding the aversive aspects of various work requirements, a study of procrastination must consider not only the magnitude of the work involved, but also the schedule of reinforcement contingent upon work requirement completion and the overall context in which work requirements are scheduled. For example, perhaps work requirements are aversive to the extent that they function similarly to other aversive events such as shock in self-control paradigms, but not to the extent that they will influence behavior when overall delays to reinforcement are confounded, as in the current experiment. 
Initial-link responses in the present procedure could be conceptualized as commitment responses, similar to those commonly examined in self-control preparations (Deluty et al., 1983; Rachlin \& Green, 1972). That is, by producing access to one of two mutually-exclusive terminal links in each trial, subjects in this procedure committed to an earlier-onset work requirement, perhaps because of the relative value of the moreimmediate reinforcer at the point at which they made the choice response. This is not the only, and perhaps not the most appropriate, procedure for producing a nonhuman laboratory analogue of procrastination. In the current procedure, as in Mazur's (1996) procedures, a choice is made at a discrete moment in time relatively removed from both the work requirements and reinforcement. Procrastination in many situations may involve relatively more temporally-influenced dynamic than static choices. Michael (1993) offered a conceptual analysis of procrastination, in which work requirement completion is maintained by negative reinforcement and responding conforms to a "procrastination scallop." That is, the combination of uncompleted work and an approaching deadline for work requirement completion interact with the passage of time in such a way that responding becomes more likely, and response rate increases, as the deadline approaches. The uncompleted work is an aversive stimulus for the organism, from which escape is possible only by work completion. Thus, the behavior engendered relative to the deadline for work completion resembles topographically the scalloped pattern typical of FI schedule performance. This conceptualization of procrastination has not been tested empirically, and remains a potentially fruitful area of research in the design of laboratory-based analogues of procrastination.

As it has been defined in the experimental analysis of behavior, procrastination is analogous to self-control choices involving aversive events, and can be analyzed against the backdrop of research in this area. Given the results of the current experiment, however, it seems pertinent that overall delays to reinforcement from the choice point be taken into account as potential controlling variables of procrastination. With the development of procedures that allow for more fluidity in choice behavior, a more finegrained analysis of procrastination will be made possible. Environmental variables that likely influence procrastination include not only the delay to the onset of the work requirements and their magnitude, but also the delay to reinforcement relative to the point in time at which the choice is made.

With the development of procedures designed to generate procrastination in laboratory settings, researchers can begin to uncover the various environmental determinants of this process. Equipped with such information, procedures can be adapted to naturalistic human settings in order to ameliorate problematic human procrastination. Only when one understands the controlling variables of procrastination is one in the position to adjust contingencies in such a way as to minimize its detrimental consequences. 
References

Ainslie, G. W. (1974). Impulse control in pigeons. Journal of the Experimental Analysis of Behavior, 21, 485-489.

Appel, J. B. (1963). Aversive aspects of a schedule of positive reinforcement. Journal of the Experimental Analysis of Behavior, 6, 423-428.

Baum, W. M. \& Rachlin, H. (1969). Choice as time allocation. Journal of the Experimental Analysis of Behavior, 12, 861-874.

Brown, P. L. \& Jenkins, H. M. (1968). Auto-shaping of the pigeon's key-peck. Journal of the Experimental Analysis of Behavior, 11, 1-8.

Catania, A. C. (1998). Learning ( $4^{\text {th }}$ ed.). New Jersey: Simon \& Schuster.

Chung, S. H. (1965). Effects of delayed reinforcement in a concurrent situation. Journal of the Experimental Analysis of Behavior, 8, 439-444.

Chung, S. H. \& Herrnstein, R. J. (1967). Choice and delay of reinforcement. Journal of the Experimental Analysis of Behavior, 10, 67-74.

Deluty, M. Z. (1978). Self-control and impulsiveness involving aversive events. Journal of Experimental Psychology: Animal Behavior Processes, 4, 250-266.

Deluty, M. Z., Whitehouse, W. G., Mellitz, M. \& Hineline, P. H. (1983). Selfcontrol and commitment involving aversive events. Behaviour Analysis Letters, 3, 213219.

Dixon, M. R., Hayes, L. J., Binder, L. M., Manthey, S., Sigman, C., \& Zdanowski, D. M. (1998). Using a self-control training procedure to increase appropriate behavior. Journal of Applied Behavior Analysis, 31, 203-210.

Encyclopaedia Britannica, Inc. (1981). The New Britannica-Webster Dictionary and Reference Guide. U.S.A: Encyclopaedia Britannica, Inc.

Fantino, E. (1968). Effects of required rates of responding upon choice. Journal of the Experimental Analysis of Behavior, 11, 15-22.

Fantino, E. (1969). Choice and rate of reinforcement. Journal of the Experimental Analysis of Behavior, 12, 723-730.

Fleshler, M., \& Hoffman, H. S. (1962). A progression for generating variableinterval schedules. Journal of the Experimental Analysis of Behavior, 5, 529-530.

Gardner, E. T. \& Lewis, P. (1976). Negative reinforcement with shockfrequency increase. Journal of the Experimental Analysis of Behavior, 25, 3-14.

Gentry, G. D., \& Marr, J. M. (1980). Choice and reinforcement delay. Journal of the Experimental Analysis of Behavior, 33, 27-37.

Green, L., Fisher, E. B., Perlow, S., \& Sherman, L. (1981). Preference reversal and self control: choice as a function of reward amount and delay. Behaviour Analysis Letters, 1, 43-51.

Green, L. \& Rachlin, H. (1996). Commitment using punishment. Journal of the Experimental Analysis of Behavior, 65, 593-601.

Green, L. \& Snyderman, M. (1980). Choice between rewards differing in amount and delay: toward a choice model of self control. Journal of the Experimental Analysis of Behavior, 34, 135-147.

Grossbard, C. L. \& Mazur, J. E. (1986). A comparison of delays and ratio requirements in self-control choice. Journal of the Experimental Analysis of Behavior, $\underline{45,305-315 .}$ 
Hineline, P. N. (1970). Negative reinforcement without shock reduction. Journal of the Experimental Analysis of Behavior, 14, 259-268.

Ito, M. \& Asaki, K. (1982). Choice behavior of rats in a concurrent-chains schedule: amount and delay of reinforcement. Journal of the Experimental Analysis of Behavior, 37, 383-392.

Leung, J. P. \& Winton, A. S. W. (1988). Preference for simple interval schedules of reinforcement in concurrent chains: effects of segmentation ratio. Journal of the Experimental Analysis of Behavior, 49, 9-20.

Mazur, J. E. (1987). An adjusting procedure for studying delayed reinforcement. In M.L. Commons, J.E. Mazur, J.A. Nevin, \& H. Rachlin (eds.), Quantitative analyses of behavior: Vol. 5. The effect of delay and of intervening events on reinforcement value (pp. 55-73). Hillsdale, NJ: Erlbaum.

Mazur, J. E. (1988). Estimation of an indifference point with an adjusting-delay procedure. Journal of the Experimental Analysis of Behavior, 49, 37-47.

Mazur, J. E. (1996). Procrastination by pigeons: preference for larger, more delayed work requirements. Journal of the Experimental Analysis of Behavior, 65, 159171.

Mazur, J. E. (1998). Procrastination by pigeons with fixed-interval response requirements. Journal of the Experimental Analysis of Behavior, 69, 185-197.

Michael, J. (1993). A behavioral perspective on college teaching. In Concepts and Principles of Behavior Analysis (pp. 109-126). Kalamazoo, MI: Association for Behavior Analysis.

Neuringer, A. J. (1969). Delayed reinforcement versus reinforcement after a fixed interval. Journal of the Experimental Analysis of Behavior, 12, 375-383.

Omino, T. A quantitative analysis of sensitivity to the conditioned reinforcing value of terminal-link stimuli in a concurrent-chains schedule. Journal of the Experimental Analysis of Behavior, 60, 587-594.

Omino, T. \& Ito, M. (1993). Choice and delay of reinforcement: effects of terminal-link stimulus and response conditions. Journal of the Experimental Analysis of Behavior, 59, 361-371.

Rachlin, H., \& Green, L. (1972). Commitment, choice and self-control. Journal of the Experimental Analysis of Behavior, 17, 15-22.

Vollmer, T. R., Borrero, J. C., Lalli, J. S., \& Daniel, D. (1999). Evaluating selfcontrol and impulsivity in children with severe behavior disorders. Journal of Applied Behavior Analysis, 32, 451-466.

Williams, B. A. \& Fantino, E. (1978). Effects on choice of reinforcement delay and conditioned reinforcement. Journal of the Experimental Analysis of Behavior, 29, 77-86. 